\title{
THE ADOPTION OF M-COMMERCE APPLICATIONS: RURAL DWELLERS' PERSPECTIVES
}

\author{
Chinedu Wilfred Okonkwo, Estelle Taylor and Magda Huisman \\ North-West University, Unit for Business Mathematics and Informatics \\ Private Bag X6001, Potchefstroom, South Africa, 2520
}

\begin{abstract}
In recent years, mobile applications (mobile apps) have gained widespread acceptance. Mobile apps services have effectively encircled most of the human activities, with the purpose of improving the living standard of the entire public. The adoption and diffusion of a mobile app are influenced by its characteristics. This study examines the adoption and diffusion of mobile commerce among the people living in a remote area of South Africa to determine the relationship between the characteristics of innovations and the adopters' attitudes. Through a survey that used diffusion of innovation as the basic framework, the opinions of the participants living in Mbongolwane in the Uthungulu District Municipality in the KwaZulu-Natal province of South Africa were gathered. A total of 120 out of 300 questionnaires distributed, were returned, giving a response rate of $40 \%$. It was found that the perceived attitudes of the rural dwellers are closely related to the characteristic of innovations as well as the adoption of mobile commerce. Also, the findings indicate that though the people are very keen to receive a new technological invention, they are still late adopters. This research work offers a support in improving the adoption and diffusion of mobile apps among the rural inhabitants.
\end{abstract}

\section{KEYWORDS}

Mobile Applications, Adoption and Diffusion, Rural Dwellers, Characteristics of Innovations, M-commerce, Attitudes

\section{INTRODUCTION}

The introduction of mobile devices like mobile phones, personal digital assistants, computers etc., has triggered the development of various kinds of mobile apps. It's a common belief that an owner of a mobile device is also an adopter and user of mobile apps. For instance, every mobile phone can be used to send an SMS message. Mobile technology services have seen extensive growth in many aspects of life activities including education, economic, government and social (Murugesan (2013), Hellstrom (2011), GSMA (2017)). In developing countries like Africa, mobile technology diffusion has seen the highest growth-rate between 2012-2017 (ITU (2017)). Mobile apps are created to be used by the public covering the urban and rural dwellers. The global economic development, in particular, the African continent, is mainly propelled by the mobile technologies (Murugesan (2013), Qiang et al. (2011)) and extending these life-changing innovations to the remote areas is highly needed. The major challenges in deploying mobile apps to rural environments include technology infrastructural costs, computer costs and internet fees and the dwellers' low computer literacy (Liu et al. (2014)).

Several studies have been conducted on the adoption and diffusion of mobile technologies (Nickerson et al. (2014), Chang (2010), Brown et al. (2003)). Most of these studies centered on the opinions of the urban dwellers. Urban areas include town and cities which are characterized by their advanced civic amenities, better education opportunities, improved transport facilities, business and social interaction and generally improved standard of living. On the hand, rural areas include villages and hamlets which are characterized by lack of overall amenities and poor standard of living. There is rapid penetration of mobile phones, especially smartphones among the rural dwellers and this has improved the adoption of mobile apps among them. In a study on the diffusion of mobile apps among rural dwellers in China, Liu et al. (2014) noted that there is a lack of empirical research on the perceptions of the rural dwellers to adopt mobile apps in the developing countries like India, China and Africa. Rogers (2003) proposed some characteristics of innovations and stated that individuals' perceptions of these characteristics predict the rate of adoption of innovations. Also, it was 
suggested that the perceptions of the characteristics of a new mobile app and other technologies (Mannan and Nordan (2014)) influence the adoption rate.

However, the relationship between the perceptions of these characteristics and the adopters' attitudes (positive, negative and nervousness) towards the adoption of mobile apps is not clear. To our knowledge, there is no study to substantiate such a relationship and it is important to conduct such a study. In this light, this study seeks to investigate the relationship between the rural dwellers' attitudes and the characteristics of innovations towards the adoption of $\mathrm{m}$-commerce apps. Based on the diffusion of innovations framework, a research model was developed and used for this study. Through a survey, quantitative data was collected and empirically evaluated.

\section{BACKGROUND INFORMATION}

Mobile apps are the mobile technological innovation of computer programs that run on mobile devices enabling users to perform their economic, political, educational and social activities irrespective of the location and context of the user. Mobile apps are developed to facilitate the functionalities of various mobile technology devices for the purpose of data gathering, information dissemination, and other activities (Okonkwo and Huisman (2018), Mc Namara (2009)). There are different types of mobile apps including mobile commerce (Bhatti (2007), Abdelkarin and Nasereddin (2010)), mobile learning (Hwang and Chang (2011)), mobile governance (Poblet (2011)), mobile agriculture (Murugesan (2013), Hellström and Tröften (2010)) and mobile health (Kumar et al. (2013)). These mobile apps are widely adopted and used in various contexts and activities across the globe (Wang et al. (2013)). This study centers on the adoption and diffusion of mobile commerce among rural dwellers.

\subsection{Mobile Commerce (M-commerce)}

M-commerce involves any commercial transaction performed through different kinds of mobile devices over a wireless network connection or telecommunication (Bhatti (2007), Joubert and Van Belle (2013), Chong (2013)). According to Bhatti (2007), there are two categories of m-commerce namely content delivery $\mathrm{m}$-commerce and transactions $\mathrm{m}$-commerce. The former involves reporting, notification and consultation while the later covers data entry, purchasing and promotions. GSMA (2015) reported that m-commerce is on a rise in African region due to rising growth of internet penetration and that $20 \%$ of South African internet users have made purchases online and another $48 \%$ are expected to do so in the future. M-commerce is important to economic growth in Africa because of ubiquitous and unison access to information and services, and the likelihood of a unique and personalized exchange of information (Bhatti (2007), San Martin et al. (2012)). The significant of $\mathrm{m}$-commerce has resulted in the establishment of digital commerce sites across the African region. In 2012, Jumia was launched in Nigeria with funding from Rocket Internet. The company has expanded beyond its original base, with local sites across many other African countries including Cameroon, Senegal, Kenya, Tanzania, Ghana and Uganda. It is also in partnership with MTN and Millicom to drive future growth and facilitates the efficiency of m-commerce among increasing mobile users (GMSA (2015)). Hellström and Tröften (2010) point out some key drivers of m-commerce as including: Increased diffusion and penetration of mobile phones; falling prices of mobile phones and services; cost-effectiveness of mobile solutions; strong branding of easy to use mobile apps; user demand and needs; need for banks to reach out and get more customers; need for operators to keep customers (loyalty); scalable agent distribution for cash-in cash-out; and fast and simple customer registration process.

There are many m-commerce apps developed and functioning actively in Africa. These include all online shopping mobile apps like Zando, Ackerman, Spree online shopping apps and many others. The purpose of this study is to investigate the association between the attitudes and perceptions of the rural dwellers on the adoption of m-commerce apps in South Africa using the people living in Mbongolwane in the Uthungulu District Municipality in the KwaZulu-Natal province as the sample population.

The use of mobile-phone-based business transaction services offers a lot of benefits including but not limited to these; long distance coverage, consumer deals, savings and easy to use and on-time service delivery (Kim (2006), Siau et al. (2003)). 


\subsection{Adoption}

Rogers (2003) defined adoption as a choice of complete acceptance and usage of a mobile technological innovation such as mobile apps. GSMA (2015) stated that adoption is acceptance and making use of a new invention. It is the user's acceptance (Lule et al. (2012)) and usage (Taylor et al. (2011)) of an innovative product such as mobile apps. Therefore, we defined adoption as the acceptance and usage of an idea or product that is perceived to be new by the adopters.

\subsection{Diffusion of Innovation Theory}

Rogers (2003) proposed a framework that has been using to measure the adoption and diffusion of technological innovations. The framework consists of four key components of the diffusion of innovations including innovation, communication channels, time, and social system. In addition, there are five categories of adopters centered on time to adoption: innovators, early adopters, early majority, late majority, and laggards. He went further to determine that adopters were unevenly spread in these categories. Also, the framework involves five characteristics of innovation that influence the rate of innovation adoption including relative advantage, compatibility, complexity, trialability and observability. Finally, he described the processes involved in innovation decision-making including knowledge, persuasion, decision, implementation and confirmation.

\section{METHODOLOGY}

Moore and Benbasat (1991) developed an instrument used to measure user's perceptions of adopting an IT innovation with diffusion theory as its basis. They noted that relative advantage and complexity are like usefulness and ease of use: hence they changed complexity to ease of use. In conclusion, they added two extra characteristics, which they believed to be significant in the adoption decision including image and voluntariness. Tan and Teo (2000) integrated the decomposed theory of planned behavior and diffusion of innovations theory to develop a framework that identified factors that may influence the adoption of internet banking. In conclusion, they included some factors to innovations characteristics which they believed to be important factors in the adoption decision including subjective norms, facilitating conditions, perceived risk and self-efficacy. Brown et al. (2003) applied the diffusion of innovations theory to determine the predictors of cell phone banking. They concluded that relative advantage, trialability, banking needs and perceived risk are the major predicting factors of cell phone banking adoption in South Africa.

The above factors were derived from the diffusion of innovation theory. These characteristics measured the adoption and diffusion of technologies in relation to the user's perception which in effect cause the perceived attitudes of the adopters. Drawing from the above previous studies, the relevant innovation characteristics which may be used to determine the relationship between the characteristics of innovations and rural dwellers adopters' attitudes on the adoption of mobile commerce include: relative advantage, compatibility, ease of use, voluntariness, facilitating conditions, self-efficacy, subjective norms and perceived risk.

A questionnaire was used as an instrument of data collection. The questionnaire contained closed-ended questions with 5-point Likert scale rating of 1 (strongly disagree) to 5 (strongly agree). The sections of the questionnaire included: Background information, mobile applications, adoption and diffusion of mobile apps, innovation characteristics, and adopter's category.

The target audience is mobile apps users residing in the rural area of Mbongolwane, a town in Uthungulu District Municipality in the KwaZulu-Natal province in South Africa. The questionnaire was administered to the participants through a self-approach system (drop off) whereby the participants were approached and convinced to complete the questionnaire. To achieve validated responses to the survey, 2 persons from that area were employed to assist us to collect responses from the participants. Also, they served as interpreters used to explain the questions in their local language to some of the participants who do not understand the English language very well. A total of 300 questionnaires were distributed to different participants and 120 $(40 \%)$ responses were returned. This research was conducted between February and March 2018. The final sample population comprises of $72(60 \%)$ males and $48(40 \%)$ females. Concerning the level of education, 88 $(73.33 \%)$ of the participants have grade $12,18(15 \%)$ have a diploma, $13(10.83 \%)$ are university degree holders and $1(0.83 \%)$ has a master's degree. Most of the participants are within the age range of 31-40. 


\section{DATA ANALYSIS}

A descriptive analysis was performed to describe the frequency and percentage of responses from the study population. A Pearson correlation analysis was performed to determine if linear relationships exist between the research variables. Cronbach alpha reliability analysis was used to compute reliability coefficients for each of the examining variables. The criterion for Cronbach's coefficient alpha for reliability is $\alpha \geq 0.6$ (Sethi and King (1991), Nunally (1978)). That is if the obtained $\alpha \geq 0.6$ then the data obtained from that particular item is reliable. In addition, multiple linear regression analysis was performed to test the relationship between the characteristics of innovation and the rural dwellers' attitudes' towards adopting mobile apps with 0.05 as significant level criteria.

\subsection{Reliability}

A reliability analysis was performed on the construct items. Cronbach's alpha indicates that the used questions reach acceptable reliability, $\alpha=0.72$. This showed that the instrument of measurement is reliable. Also, the correlation scores of all the items are identical $(r=1)$ which indicates that the construct items correlate with each other. This is possible because the study was conducted in a unique domain where the perceptions and attitudes of the participants are similar. The reliability results are: Compatibility $(\alpha=0.68)$, Relative advantage $(\alpha=0.67)$, Voluntariness $(\alpha=0.64)$, Subjective norms $(\alpha=0.64)$, Ease of use $(\alpha=0.72)$, Perceived risk $(\alpha=0.64)$, Facilitating conditions $(\alpha=0.8)$ and Self-efficacy $(\alpha=0.69)$.

\subsection{Survey Results}

The obtained results from the collected data are presented as follows:

Mobile apps - this section tested the knowledge of, and the use of mobile apps. A larger percentage of the participants agreed to know about mobile apps and have used them in various activities including $120(100 \%)$ for SMS, social networking and entertainment, $10 \%$ for agriculture, $40 \%$ for education and $20 \%$ for commerce.

Adoption and diffusion of mobile apps - this section tested the participants' attitudes towards a new mobile app. With regards to the individual reaction whenever he/she heard of a new mobile app, 60 (50\%) are positive, $13(10.8 \%)$ are negative and $47(39.2 \%)$ are indifferent. Concerning nervousness on adopting a new mobile app, 61 (50.8) are not nervous, 26 (21.6\%) are nervous and 33 (27.5\%) are neutral. 93 (77.5\%) of the participants strongly agreed that their main purpose of using mobile apps is for easy communications while $44(36.6 \%)$ used mobile apps for other activities including online shopping. Also, 96 (80\%) agreed that, from the time they get to know about a new mobile app, it takes them between 1-3 months to adopt and use it.

Innovation characteristics - this section tested the perceptions of the participants on the characteristics of innovations.

Relative advantage - is the extent to which an innovation is observed to be better than the existing ones. The obtained results are: $47(39.2 \%)$ of the participants agreed that the relative advantage of a mobile app influences their adoption of that mobile app, 49 (40.8\%) are neutral about the impact of this factor and 24 $(20 \%)$ disagreed on this factor.

Compatibility - is the degree to which the innovation fits well with the existing values, experiences, and needs of possible adopters. The obtained results are: $57(47.5 \%)$ of the participants agreed that the compatibility of a mobile app influences their adoption of that mobile app, $45(37.5 \%)$ are neutral about the impact of this factor and $18(15 \%)$ disagreed on this factor.

Ease of use - is the extent to which the innovation seems easy to be used. The obtained results are: 57 (47.5\%) of the participants agreed that the ease of use of a mobile app influences their adoption of that mobile app, 39 (32.5\%) are neutral about the impact of this factor and 24 (20\%) disagreed on this factor.

Voluntariness - is the degree to which use of the innovation is perceived as being of free will. The obtained results are: $59(49.1 \%)$ of the participants agreed that the voluntariness of a mobile app influences their adoption of that mobile app, $37(30.9 \%)$ are neutral about the impact of this factor and $24(20 \%)$ disagreed on this factor. 
Facilitating conditions - are the supports provided by service providers and the government. The obtained results are: $63(52.5 \%)$ of the participants agreed that the facilitating conditions of a mobile app influence their adoption of that mobile app, 33 (27.5\%) are neutral about the impact of this factor and 24 $(20 \%)$ disagreed on this factor.

Self-efficacy - is the individual ability to use an innovation. The obtained results are: $87(72.2 \%)$ of the participants agreed that the self-efficacy of a mobile app influences their adoption of that mobile app, 11 $(9.2 \%)$ are neutral about the impact of this factor and $22(18.4 \%)$ disagreed on this factor.

Subjective norms - is the individual perception that most people who are important think that he/she should perform a behaviour. The obtained results are: $61(50.9 \%)$ of the participants agreed that the subjective norms of a mobile app influence their adoption of that mobile app, $48(40 \%)$ are neutral about the impact of this factor and $11(9.2 \%)$ disagreed on this factor.

Perceived risk - is the danger involves in using an innovation. The obtained results are: $49(40.8 \%)$ of the participants agreed that the perceived risk of a mobile app influences their adoption of that mobile app, 49 $(40.8 \%)$ are neutral about the impact of this factor and $22(18.4 \%)$ disagree on this factor.

Adopter's category - this section determines the types of adopter each of the participants is.

Innovators - they are the set of adopters that are willing to experience a new innovation irrespective of the profit, loss or risk involved. The obtained results are: $22(18.3 \%)$ of the participants agreed to be in this category of adopters, $11(9.2 \%)$ are neutral about the category and $87(72.5 \%)$ are not in this category.

Early adopters - they are leaders and advisers of the social system and their actions are limited within the boundaries of the social system. The obtained results are: $11(9.2 \%)$ of the participants agreed to be in this category of adopters, $11(9.2 \%)$ are neutral about the category and 98 (81.6) are not in this category.

Early majority - they are non-leaders with good interpersonal networks, deliberate in adopting an innovation and they are neither the first nor the last to adopt the innovation. The obtained results are: 49 $(40.8 \%)$ of the participants agreed to be in this category of adopters, $35(29.2 \%)$ are neutral about the category and $36(30 \%)$ are not in this category.

Late majority - they are the set of adopters that are skeptical about adopting an innovation and wait for most people to adopt it first. The obtained results are: $83(69.2 \%)$ of the participants agreed to be in this category of adopters, $13(10.8 \%)$ are neutral about the category and $24(20 \%)$ are not in this category.

Laggards - they are the most localized group in the social system with traditional view and very much skeptical about adopting a new idea. The obtained results are: $71(59.2 \%)$ of the participants agreed to be in this category of adopters, $38(31.7 \%)$ are neutral about the category and $11(9.2 \%)$ are not in this category.

\subsection{Adopters Attitudes}

For this research, attitude is defined as an individual's beliefs and feelings over an innovation. The attitudes of an adopter may be positive, negative and nervousness towards the adoption and rejection of an innovation. Wang et al. (2008) suggested that attitudes are a major predicting factor influencing the adoption of a new product, therefore there is a need for more understanding of attitudes in a well-defined manner. Attitudes are considered to be a three-factor concept comprising of cognitive, affective and conative covering thoughts and beliefs, feelings and actions respectively (Prislin and Crano (2008)).

This study seeks to determine the relationship between the characteristics of innovations and adopters' attitudes among rural dwellers on the adoption of m-commerce. Applying regression analysis to the research model whereby the characteristics of innovations are the independent variables and the perceived attitudes are the dependent variable, the results obtained are shown in Table 1 - Table 3.

Table 1 indicates that relative advantage, voluntariness, subjective norms, perceived risk, facilitating conditions and self-efficacy characteristics showed statistical significant predictive capability. This means that these characteristics have an impact on the positive attitudes of the rural dwellers towards the adoption of m-commerce apps. 
Table 1. Positive Attitudes

\begin{tabular}{|c|c|c|c|c|c|c|}
\hline \multirow{2}{*}{\multicolumn{2}{|c|}{ Model }} & \multicolumn{2}{|c|}{ Unstandardized Coefficients } & \multirow{2}{*}{$\begin{array}{l}\text { Standardized Coefficients } \\
\text { Beta }\end{array}$} & \multirow[b]{2}{*}{$\mathrm{t}$} & \multirow[b]{2}{*}{ Sig. } \\
\hline & & B & Std. Error & & & \\
\hline \multirow[t]{9}{*}{1} & (Constant) & 2.190 & .614 & & 3.565 & .001 \\
\hline & Compatibility & -.200 & .121 & -.137 & -1.646 & .103 \\
\hline & Relative advantage & .569 & .127 & .527 & 4.475 & .000 \\
\hline & Voluntariness & -.792 & .175 & -.641 & -4.519 & .000 \\
\hline & Subjective norms & 1.839 & .213 & 1.018 & 8.615 & .000 \\
\hline & Ease of use & -.115 & .100 & -.077 & -1.143 & .255 \\
\hline & Perceived risk & .314 & .157 & .220 & 1.998 & .048 \\
\hline & Facilitating conditions & -.579 & .108 & -.357 & -5.356 & .000 \\
\hline & Self-efficacy & -.694 & .115 & -.643 & -6.029 & .000 \\
\hline
\end{tabular}

Table 2. Negative Attitudes

\begin{tabular}{|c|c|c|c|c|c|c|}
\hline \multirow{2}{*}{\multicolumn{2}{|c|}{ Model }} & \multicolumn{2}{|c|}{ Unstandardized Coefficients } & \multirow{2}{*}{$\begin{array}{l}\text { Standardized Coefficients } \\
\text { Beta }\end{array}$} & \multirow[b]{2}{*}{$\mathrm{t}$} & \multirow[b]{2}{*}{ Sig. } \\
\hline & & $\mathrm{B}$ & Std. Error & & & \\
\hline \multirow[t]{9}{*}{1} & (Constant) & 3.160 & .673 & & 4.697 & .000 \\
\hline & Compatibility & -.054 & .133 & -.052 & -.406 & .686 \\
\hline & Relative advantage & -.660 & .139 & -.858 & -4.739 & .000 \\
\hline & Voluntariness & .531 & .192 & .603 & 2.764 & .007 \\
\hline & Subjective norms & -.371 & .234 & -.288 & -1.588 & .115 \\
\hline & Ease of use & .157 & .110 & .147 & 1.423 & .158 \\
\hline & Perceived risk & .028 & .172 & .027 & .162 & .871 \\
\hline & Facilitating conditions & .112 & .118 & .097 & .943 & .348 \\
\hline & Self-efficacy & .015 & .126 & .020 & .123 & .903 \\
\hline
\end{tabular}

Table 2 indicates that relative advantage and voluntariness characteristics showed statistical significant predictive capability. This means that these characteristics have an impact on the negative attitudes of the rural dwellers towards the adoption of $\mathrm{m}$-commerce apps.

Table 3. Nervous Attitudes

\begin{tabular}{|c|c|c|c|c|c|c|}
\hline \multirow{2}{*}{\multicolumn{2}{|c|}{ Model }} & \multicolumn{2}{|c|}{ Unstandardized Coefficients } & \multirow{2}{*}{$\begin{array}{l}\text { Standardized Coefficients } \\
\text { Beta }\end{array}$} & \multirow[b]{2}{*}{$\mathrm{t}$} & \multirow[b]{2}{*}{ Sig. } \\
\hline & & B & Std. Error & & & \\
\hline \multirow[t]{9}{*}{1} & (Constant) & 3.493 & .364 & & 9.606 & .000 \\
\hline & Compatibility & .182 & .072 & .150 & 2.535 & .013 \\
\hline & Relative advantage & -1.380 & .075 & -1.538 & -18.327 & .000 \\
\hline & Voluntariness & 1.240 & .104 & 1.208 & 11.950 & .000 \\
\hline & Subjective norms & -1.438 & .126 & -.957 & -11.377 & .000 \\
\hline & Ease of use & .332 & .059 & .268 & 5.580 & .000 \\
\hline & Perceived risk & .846 & .093 & .712 & 9.082 & .000 \\
\hline & Facilitating conditions & .092 & .064 & .068 & 1.438 & .153 \\
\hline & Self-efficacy & -.060 & .068 & -.067 & -.882 & .380 \\
\hline
\end{tabular}

Table 3 indicates that compatibility, relative advantage, voluntariness, subjective norms, ease of use and perceived risk characteristics showed statistical significant predictive capability. This means that these characteristics have an impact on the nervous attitudes of the rural dwellers towards the adoption of m-commerce apps.

\section{INTERPRETATION OF THE RESULTS}

Generally, the results indicated that the rural dwellers have a good knowledge of what mobile apps are about, though not familiar with using all. For instance, all the participants are users of the SMS app. This is because they are using mobile phones for telephony and messages communications. With regards to m-commerce, a little portion $(20 \%)$ of the sample population has knowledge of it and has used it. This implies that there is a 
lack of awareness-knowledge of m-commerce apps among the rural inhabitants and there is a need to create more awareness-knowledge about m-commerce and other related mobile apps.

A larger number of the rural dwellers perceived m-commerce app to be a good technological innovation and are willing to adopt and use them without being nervous at all. In addition, the results revealed that the rural dwellers show positive attitudes when they hear of a new mobile app. Therefore, it implies that they are willing, ready to accept, learn how to and practically use an innovation that get to their reach. They adopt and use mobile apps mostly for communications purposes like SMS, social networking and entertainments. Although they have limited awareness-knowledge of m-commerce apps, they demonstrated to have a high rate of interest in adopting and using m-commerce apps such that it takes an average range of 1-3 months for them to adopt and use a new mobile app.

Eight characteristics of innovations were used to examine the perceptions and attitudes of the rural dwellers on the adoption and diffusion of m-commerce including relative advantage, compatibility, ease of use, voluntariness, facilitating conditions, self-efficacy, subjective norms and perceived risk. The obtained results revealed that the rural dwellers perceived the innovation characteristics to be significant factors in their decision-making either to accept or reject m-commerce. Thus, the characteristics of innovations influence the attitudes of the rural dwellers towards decision-making on the adoption and diffusion of m-commerce apps.

The rural dwellers demonstrated a good intention of embracing a new technological innovation but still, they fall in the late majority and laggards categories. Probably because they live in a remote area and extension of the knowledge about a new innovation comes late. This suggests that if the information about an innovation like m-commerce apps is being disseminated to the rural areas in due time as it is done in the urban areas, there is the possibility that some rural dwellers will be in the early adopters and innovators categories.

Multiple linear regression analysis was performed to investigate the relationship between the characteristics of innovations and the rural dwellers' attitudes. The obtained results indicated that all the 8 tested characteristics of innovations have statistical significant capabilities of influencing the rural dwellers' attitudes (positive, negative or nervous) towards the adoption of m-commerce.

Concerning positive attitudes, the relative advantage, voluntariness, subjective norms, perceived risk, facilitating conditions and self-efficacy characteristics have significant influences towards the positive attitudes of the rural dwellers' adopters. This suggests that changes to these characteristics result in changes to the adopters' attitudes. With respects to the negative attitudes, the relative advantage and voluntariness characteristics have significant influences towards the negative attitudes of the rural dwellers' adopters. In relation to nervous attitudes, the compatibility, relative advantage, voluntariness, subjective norms, ease of use and perceived risk characteristics have a significant influence on the nervous attitudes of the rural dwellers' attitudes.

The analyses show that there exists a clear relationship between the perceived attitudes of the rural dwellers and the characteristics of innovations. From the perspectives of the rural dwellers, the adopters of mobile apps believe that an innovation should have a relative advantage over the existing ones, fits well into their lifestyle, be easy for them to learn and use, and with necessary support both from the innovators and the government. Furthermore, with the acquisition of the required knowledge and free decision to use the innovation, it must be in line with their societal norms and with reduced risk. Moreover, the rural dwellers exhibit positive interest whenever they get to know about a new mobile app which activated their enthusiasm to adopt and use the mobile app without panic.

\section{REFERENCES}

Abdelkarim, A. and Nasereddin, H., 2010. Mobile commerce. Journal of Mathematics and Technology, Vol. 4, No. 1, pp. 51-56.

Bhatti, T., 2007. Exploring factors influencing the adoption of mobile commerce. The Journal of Internet Banking and Commerce, Vol. 12, No. 3.

Brown, I., et al., 2003. Cell phone banking: predictors of adoption in South Africa — an exploratory study. International journal of information management, Vol. 23, No. 5, pp. 381-394.

Chang, H., C., 2010. A new perspective on Twitter hashtag use: Diffusion of innovation theory. Proceedings of the American Society for Information Science and Technology, Vol. 47, No. 1, pp. 1-4. 
Chong, A.Y.-L., 2013. Mobile commerce usage activities: The roles of demographic and motivation variables. Technological Forecasting and Social Change, Vol.80, No. 7, pp. 1350-1359.

GSMA, 2017. The Mobile Economy Sub-Saharan 2017. https://www.gsmaintelligence.com/research/?file=7bf3592e6d750144e58d9dcfac6adfab\&download.

GSMA, 2015. The mobile economy 2015, GSMA, Editor. GSM Association. p. 1-62.

Hellström, J.,2011. Mobile governance: Applications, challenges and scaling-up. Mobile Technologies for Conflict Management, Springer. pp. 159-179.

Hellström, J. and Tröften, P.-E., 2010. The innovative use of mobile applications in East Africa. Swedish international development cooperation agency (Sida).

Hwang, G.-J. and Chang H.-F., 2011. A formative assessment-based mobile learning approach to improving the learning attitudes and achievements of students. Computers \& Education, Vol 56, No. 4, pp. 1023-1031.

ITU, 2017. ITU releases 2017 global information and communication technology facts and figures. http://news.itu.int/ itu-releases-2017-global-information-and-communication-technology-facts-and-figures/

Joubert, J. and Van Belle, J., 2013. The role of trust and risk in mobile commerce adoption within South Africa. International Journal of Business, Humanities and Technology, Vol. 3, No. 2, pp. 27-38.

Kim, S.H., 2006. Impact of mobile-commerce: benefits, technological and strategic issues and implementation. Journal of Applied Sciences, Vol. 6, No. 12., pp. 2523-2531.

Kumar, S., et al., 2013. Mobile health technology evaluation: the mHealth evidence workshop. American Journal of Preventive medicine, Vol.45, No. 2, pp. 228-236.

Liu, Y., et al., 2014. An empirical investigation of mobile government adoption in rural China: A case study in Zhejiang province. Government Information Quarterly, Vol. 31, No. 3, pp. 432-442.

Lule, I., et al., 2012. Application of technology acceptance model (TAM) in m-banking adoption in Kenya. International Journal of Computing and ICT Research, Vol. 6, No. 1, pp. 31-43.

Mannan, S. and Nordin, S.M., 2014. The Influence of Innovation Attributes on New Technologies Adoption by Paddy Farmers. International Review of Management and Business Research, Vol. 3, No. 3, p. 1379.

Mc Namara, K.S., 2009. Mobile Applications in Agriculture and Rural Development-Framing the Topic, and Learning from Experience. World Bank Workshop on Mobile Innovations for Social and Economic Transformation.

Moore G.C. and Benbasat I., 1991. Development of an instrument to measure the perceptions of adopting an information technology innovation. Information Systems Research, Vol. 2, No. 3, pp. 192-222.

Murugesan, S., 2013. Mobile apps in Africa. IT Professional, Vol. 15, No. 5, pp. 8-11.

Nickerson, R., et al., 2014. Mobile Technology and Smartphone Apps: A Diffusion of Innovations Analysis. Proceedings of the $20^{\text {th }}$ Twentieth Americas Conference on Information Systems, Savannah, USA, pp. 1-12.

Numally, J.C.,1978. Psychometric theory. NY: McGraw-Hill, 1978.

Okonkwo, W.C. and Huisman, M., 2018. The Use of System Development Methodologies in the Development of Mobile Applications: Are they Worthy of Use? IEEE 42nd Annual Computer Software and Applications Conference (COMPSAC). Tokyo, Japan, pp. 278-283.

Poblet, M., 2011. Rule of Law on the Go: New Developments of Mobile Governance. J. UCS, Vol.17, No.3, pp. 498-512.

Prislin, R. and Crano, W.D., 2008. Attitudes and attitude change. New York: Psychology Press.

Qiang, C.Z., et al., 2011. Mobile applications for agriculture and rural development. World Bank, Washington, DC.

Rogers, E., 2003. Diffusion of Innovations (5th ed). New York: Free Press.

San Martín, S., B., et al., 2012. Factors determining firms' perceived performance of mobile commerce. Industrial Management \& Data Systems, Vol. 112, No. 6, pp. 946-963.

Sethi, V. and King, W.R., 1991. Construct measurement in information systems research: An illustration in strategic systems. Decision Sciences, Vol.22, No.2, pp. 455-472.

Siau, K., et al., 2003. Mobile commerce: Current states and future trends. Advances in mobile commerce technologies, IGI Global. p. 1-17.

Tan, M. and Teo, TSH, 2000. Factors influencing the adoption of Internet Banking. Journal of the Association for Information Systems, Vol.1, Issue 1, Article 5. https://aisel.aisnet.org/jais/vol2/iss 1/5

Taylor, D.G., et al., 2011. Mobile application adoption by young adults: A social network perspective. WCOB Faculty Publications. Paper 1. http://digitalcommons.sacredheart.edu/wcob_fac/1

Wang, H.-Y., et al., 2013. What affects mobile application use? The roles of consumption values. International Journal of Marketing Studies, Vol. 5, No. 2, p. 11.

Wang, G., et al., 2008. Consumption attitudes and adoption of new consumer products: a contingency approach. European Journal of Marketing, Vol. 42, No. 1/2, pp. 238-254. 